University of Massachusetts Amherst

ScholarWorks@UMass Amherst

Chemistry Department Faculty Publication Series

Chemistry

2009

\title{
Determination of lead in wine and rum samples by flow injection-hydride generation-atomic absorption spectrometry
}

L Elci

Z Arslan

JF Tyson

Follow this and additional works at: https://scholarworks.umass.edu/chem_faculty_pubs

Part of the Chemistry Commons

\section{Recommended Citation}

Elci, L; Arslan, Z; and Tyson, JF, "Determination of lead in wine and rum samples by flow injection-hydride generation-atomic absorption spectrometry" (2009). Journal of Hazardous Materials. 996.

Retrieved from https://scholarworks.umass.edu/chem_faculty_pubs/996 


\title{
Determination of lead in wine and rum samples by flow injection-hydride generation-atomic absorption spectrometry
}

\author{
Latif Elçị ${ }^{\mathrm{a}, *}$, Zikri Arslan $^{\mathrm{b}}$, Julian F. Tyson ${ }^{\mathrm{c}}$ \\ a Department of Chemistry, University of Pamukkale, Denizli TR-20020, Turkey \\ b Department of Chemistry, Jackson State University, P.O. Box 17910, Jackson, MS, 39217-0510, USA \\ ' Department of Chemistry, University of Massachusetts, Box 34510, Amherst, MA, 01003-4510, USA
}

A B S T R A C T

A method for direct determination of lead in wine and rum samples was developed, using a flow injection hydride generation system coupled to an atomic absorption spectrometer with flame-quartz atomizer (FI-HG-AAS). Lead hyride $\left(\mathrm{PbH}_{4}\right)$ was generated using potassium ferricyanide $\left(\mathrm{K}_{3} \mathrm{Fe}(\mathrm{CN})_{6}\right)$, as oxidant and sodium tetrahydroborate $\left(\mathrm{NaBH}_{4}\right)$ as reductant. Samples were acidified to $0.40 \%(\mathrm{v} / \mathrm{v}) \mathrm{HCl}$ for wine and to $0.30 \%(\mathrm{v} / \mathrm{v}) \mathrm{HCl}$ for rum, which were then mixed on-line with $3 \%(\mathrm{~m} / \mathrm{v}) \mathrm{K}_{3} \mathrm{Fe}(\mathrm{CN})_{6}$ solution in $0.03 \%(\mathrm{v} / \mathrm{v})$ $\mathrm{HCl}$ prior to reaction with $0.2 \%(\mathrm{~m} / \mathrm{v})$ alkaline $\mathrm{NaBH}_{4}$ solution. Lead contents of a rum and two different red wine samples were determined by FI-HG-AAS agreed with those obtained by ICP-MS. The analytical figures of merit of method developed were determined. The calibration curve was linear up to $8.0 \mu \mathrm{g} \mathrm{L}^{-1} \mathrm{~Pb}$ with a regression coefficient of 0.998 . The relative error was lower than $4.58 \%$. The relative standard deviation $(n=7)$ was better than $12 \%$. A detection limit of $0.16 \mu \mathrm{g} \mathrm{L}^{-1}$ was achieved for a sample volume of $170 \mu \mathrm{L}$.

\section{Introduction}

Due to the increasing global environmental pollution, systematic monitoring of toxic heavy metals in food and beverages is very important to protect the public health against the dietary exposure to these metals. Lead $(\mathrm{Pb})$ is a widely known toxic heavy metal whose toxic properties are well-documented [1,2]. An excess of ingested lead is a real health hazard affecting both the nervous system and the biosynthesis of hemoglobin [1]. In response to this health concern, the threshold limit value of $\mathrm{Pb}$ in wine has been reduced progressively by the International Organization of Vine and Wine (OIV), and is at present $200 \mu \mathrm{g} / \mathrm{L}$ [3]. Nevertheless, the permissible level of $\mathrm{Pb}$ in wine varies between 200 and $300 \mu \mathrm{g} \mathrm{L}^{-1}$ in different countries, which are below the detection limits of conventional flame atomic absorption spectrometry (FAAS). The use of FAAS for determination of lead requires either preconcentration or hydride generation procedure. Hydride generation is one of the most popular analytical methods for the determination of trace or ultratrace levels of several hydride-forming elements, including lead in combination with various atomic spectrometry techniques [4]. Because, it improves transfer efficiency of the gaseous lead hydride (plumbane) into the quartz tube atomizer that in turn allows lower detection limits to be achieved for the determina-

\footnotetext{
* Corresponding author. Tel.: +90 25829635 64; fax: +90 2582963593 . E-mail address: elci@pau.edu.tr (L. Elçi).
}

tion of $\mathrm{Pb}$. In addition, hydride generation can readily separate the species of interest from the undesirable matrix components.

Little work has been done on lead hydride generation in comparison with other hydride forming elements, such as arsenic, selenium and antimony; most likely due to the low yield and thermal instability of plumbane $\left(\mathrm{PbH}_{4}\right)$ [4,5]. Generation of lead hydride depends largely on the experimental conditions used, therefore, previous studies have mainly focused on the nature of the acids and oxidizing agents, and their roles in the generation of plumbane. Most common oxidizing agents used in presence of various acids include hydrogen peroxide [6-9], ammonium or sodium peroxodisulphate $[6,10,11]$, potassium dichromate $[6,8,11]$ and potassium ferricyanide $[11,12]$. Depending on the type of oxidizing agent, it was reported that the use of acidic oxidizing media increased the reaction rate and sensitivity via efficient oxidation of $\mathrm{Pb}$ (II) to an unstable intermediate, $\mathrm{Pb}(\mathrm{IV})$, to form plumbane, $\mathrm{PbH}_{4},[5,6,13,14]$. Better sensitivity was reported by using potassium ferricyanide, $\mathrm{K}_{3} \mathrm{Fe}(\mathrm{CN})_{6}$ ), a relatively mild oxidant [15-20]. Lead hydride generation with a mixture of potassium ferricyanide and hydrochloric or nitric acid has been successfully applied to the determination of $\mathrm{Pb}$ in various samples, including soil and sediments [18,19], calcium matrices [20,21], urine [17], dialysis concentrates [15], geochemical deposits and paint [22].

The generation of lead hydride is also an attractive method for analysis of non-aqueous solutions for $\mathrm{Pb}$. The hydride generation has been used for determination of $\mathrm{Pb}$ in gasoline [23] and in chloroform extracts of lead pyrrolidine-1-carbodithioate from particulate 
matter [24]. A great deal of effort has been spent to develop a robust and reliable method for analysis of alcoholic beverages, such as wine. Wine is a complex sample containing a variety of inorganic as well as organic substances in an ethanol-aqueous solution. There are few studies of lead hydride generation in wines those that include the batch mode generation of lead hydride with or without mineralization of the samples [9,25-29].

In this paper, we desribed a method developed to achieve direct determination of $\mathrm{Pb}$ from alcoholic drinks by hydride generation FAAS using flow injection technique which, compared to batch or off-line methods, affords better precision and freedom from interferences in hydride generation. The effects of various parameters, such as sample acidity, potassium ferricyanide concentration and flow rate, argon stripping gas flow rate, were discussed on the generation of plumbane. The results obtained from wine and rum samples were compared with those from an ICP-MS reference method [30].

\section{Experimental}

\subsection{Reagents}

All reagents were of analytical-reagent grade. High-purity deionized water $(18 \mathrm{M} \Omega \mathrm{cm})$ was used throughout the experiments. A stock solution of $1000 \mathrm{mg} \mathrm{L}^{-1}$ of lead (Aldrich) was used to prepare standard and test solutions. Sodium borohydride solution $\left(\mathrm{NaBH}_{4}, 0.2 \%, \mathrm{~m} / \mathrm{v}\right)$ was freshly prepared daily by dissolving the appropriate amount of $\mathrm{NaBH}_{4}(98 \%$ pure, Alfa) in $0.05 \%(\mathrm{~m} / \mathrm{v})$ sodium hydroxide solution. Potassium ferricyanide solution $(3 \%$, $\mathrm{m} / \mathrm{v}$ ) was prepared freshly by dissolving the appropriate amount of $\mathrm{K}_{3} \mathrm{Fe}(\mathrm{CN})_{6}$ (Aldrich) in $0.03 \%(\mathrm{v} / \mathrm{v}) \mathrm{HCl}$ solution (Fisher Scientific).

\subsection{Apparatus}

A PerkinElmer (Norwalk, CT, USA) Model 1100 B atomic absorption spectrometer with deuterium background correction was used. An intensitron (PerkinElmer) lead hollow cathode lamp, operated at $7 \mathrm{~mA}$, was used at $283.3 \mathrm{~nm}$ with a $0.7-\mathrm{nm}$ spectral bandpass. Data were recorded by an Epson Model LQ-850 printer. For ICP-MS determinations of $\mathrm{Pb}$ in wine samples, a PerkinElmer SCIEX Elan 5000 ICP-MS instrument was used.

A T-shaped quartz tube (PerkinElmer) was used as the atomization cell that was mounted on an acetylene/air flame. An air-acetylene flame was employed with gas flow rates of 10.0 and $1.5 \mathrm{~L} \mathrm{~min}^{-1}$ for air and acetylene, respectively. The efficiency of the atomization within a quartz tube was dependent on the physical state of the quartz surface [14,18]. Further, transfer of aqueous components and reagents from the gas-liquid separator to the inte- rior of the tube reduced the sensitivity gradually; therefore, the quartz tube was soaked in $40(\mathrm{v} / \mathrm{v})$ hydrofluoric acid for $15 \mathrm{~min}$ each day.

The schematic diagram of the flow injection manifold built on a PerkinElmer FIAS 200 unit is shown in Fig. 1. Pump 1 was used for the sample solution with a flow rate of $5.4 \mathrm{~mL} \mathrm{~min}^{-1}$ (pump tube i.d., $1.52 \mathrm{~mm}$, color code; blue-yellow). Pump 2 delivered the carrier (deionized water) at $5.4 \mathrm{~mL} \mathrm{~min}^{-1}$ (color code of pump tube; blue-yellow), the potassium ferricyanide solution (oxidant) at $11.4 \mathrm{~mL} \mathrm{~min}-1$ (color code of pump tube; purple-purple) and the sodium borohydride solution at $5.4 \mathrm{~mL} \mathrm{~min}^{-1}$ (color code of pump tube; blue-yellow). All connecting tubes were made up of $0.8 \mathrm{~mm}$ i.d. PTFE tubing. A PerkinElmer gas-liquid separator with glass beads (PerkinElmer part no. B019-3772) was used. The chemfold was also from PerkinElmer. The flow rate of argon gas as carrier was $22 \mathrm{~mL} \mathrm{~min}^{-1}$, unless stated otherwise. The size of the sample loop was $170 \mu \mathrm{L}$.

\subsection{Procedure}

Red wine (Italian and Californian) and rum samples purchased from a local store were analysed for $\mathrm{Pb}$ content directly after diluting with water and acidifiying with concentrated hydrochloric acid. One milliliter of Italian red wine was taken from the bottled wine using an Eppendorf micropipet and transferred into a $10 \mathrm{~mL}$ volumetric flask. The sample was acidified by adding $40 \mu \mathrm{L}$ of concentrated $\mathrm{HCl}$ and then diluted to the mark with the deionized water. The same procedure was applied to $1.5 \mathrm{~mL}$ of a Californian red wine. For the determination of $\mathrm{Pb}$ in rum from Trinidad, $10 \mathrm{~mL}$ of rum sample from the bottled solution was acidified with $30 \mu \mathrm{L}$ of concentrated $\mathrm{HCl}$. The $\mathrm{Pb}$ content of the samples was determined by FI-HG-AAS method optimized in this study. External calibration was performed with aqueous standards that ranged from 0.0 to $8.0 \mu \mathrm{g} \mathrm{L}^{-1} \mathrm{~Pb}$ prepared in $0.30 \%(\mathrm{v} / \mathrm{v}) \mathrm{HCl}$ solution.

\subsection{Method development and optimization}

There were a number of considerations for the optimization study: detection limit (LOD), signal to noise ratio (S/N) and throughput. One goal was to obtain sufficient detection capability to allow the measurement of lead at concentrations of around $1 \mu \mathrm{g} \mathrm{L}^{-1}$, this meant that a detection limit of about $0.1 \mu \mathrm{g} \mathrm{L}^{-1}$ was desirable. For measurements to be useful, it was considered that a relative standard deviation (RSD) of about $10 \%$ was acceptable, and that the basewidth of the peak should not be wider than $3.0 \mathrm{~s}$. This latter parameter was considered of minor importance in comparison with those of LOD and S/N. The optimization strategy adopted, for reasons discussed below, was the single-cycle alternating variable search with peak height as the figure of merit to be maximized.

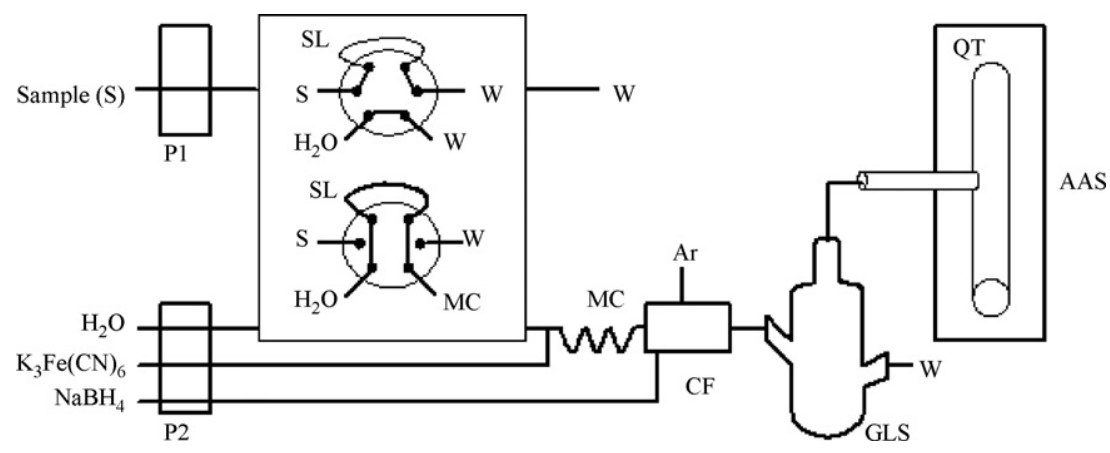

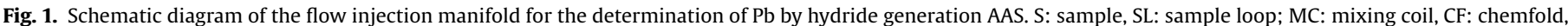
GLS: gas-liquid separator, W: waste, QT: quartz T-atomizer. 
Conditions which produced double peaks or other distorted peak shapes were considered sub-optimal as were conditions which produced relative standard deviation of greater than $10 \%$.

The relevant parameters include manifold design, sample volume, flow rates and concentrations of the various reagents and carrier streams, lengths of tubing between confluence points, argon gas flow rate, gas-liquid separator design, dimensions of transfer tubing, atomizer design and temperature. The starting conditions were selected on the basis of a previous work [12].

A three-line manifold was chosen in which the sample was injected into a carrier, merged with oxidant, then with hydride generation reagent and with finally argon stripping gas. This design avoided the need for addition of oxidant to the sample before injection into the manifold. The minimum dilution in the manifold would be obtained by a design in which a large volume was injected. Residence times can be controlled by variation of both tube dimensions and flow rates. Reagent concentrations in the manifold are controlled by concentrations in the reservoirs and the flow rates of the streams which merge at the confluence points. Some features of the gas-liquid separation can be controlled by the flow rate of argon, which also influences the transfer to the atomizer and dilution in the gas phase.

\subsection{Initial optimization of conditions}

A $4 \mu \mathrm{g} \mathrm{L}^{-1} \mathrm{~Pb}$ test solution in $0.3 \%(\mathrm{v} / \mathrm{v}) \mathrm{HCl}$ was used to optimize the flow rate of argon stripping gas, the volume of sample, the length of mixing coil and the length of reaction coil. Solutions of $\mathrm{K}_{3} \mathrm{Fe}(\mathrm{CN})_{6}(3 \% \mathrm{~m} / \mathrm{v})$ and $\mathrm{NaBH}_{4}(0.2 \% \mathrm{~m} / \mathrm{v})$ used in these experiments were prepared in $0.03 \%(\mathrm{v} / \mathrm{v}) \mathrm{HCl}$ and $0.05 \%(\mathrm{~m} / \mathrm{v}) \mathrm{NaOH}$, respectively.

Initially, a flow rate was set to $4.2 \mathrm{~mL} \mathrm{~min}^{-1}$ for all solutions. The argon carrier gas flow rate was varied from 10 to $100 \mathrm{~mL} \mathrm{~min}^{-1}$ to examine the effect on the peak height absorbance of $\mathrm{Pb}$. The oxidation of $\mathrm{Pb}(\mathrm{II})$ to $\mathrm{Pb}(\mathrm{IV})$ by $\mathrm{K}_{3} \mathrm{Fe}(\mathrm{CN})_{6}$ occurs within the mixing coil, and thus, the length of mixing coil ( $0.8 \mathrm{~mm}$ i.d. PTFE tubing) was evaluated between 25 and $75 \mathrm{~cm}$ to find the optimum length that ensures quantitative oxidation of lead. The length of the reaction coil ( $0.8 \mathrm{~mm}$ i.d. PTFE) was also varied between 15 and $30 \mathrm{~cm}$ to affect the generation of plumbane $\left(\mathrm{PbH}_{4}\right)$. Finally, the volume of sample loop was varied from 100 to $400 \mu \mathrm{L}$ to affect the sensitivity and peak height signal shape.

The height of the absorbance signal was strongly dependent on the flow rates of the carrier including sample and potassium ferricyanide (oxidant) solutions. Thus, in the second stage of the optimization, the flow rates of these solutions were optimized by varying from 4.2 to $11.4 \mathrm{~mL} \mathrm{~min}^{-1}$ for carrier and $4.2-12.6 \mathrm{~mL} \mathrm{~min}^{-1}$ for potassium ferricyanide. The flow rate of the reductant $\left(\mathrm{NaBH}_{4}\right)$ was also examined for efficient generation of plumbane. Acidity of the sample solution was another critical factor that influenced the generation lead hydride [12]. Thus, the effect of hydrochloric acid concentration was studied from 0 to $1 \%(\mathrm{v} / \mathrm{v}) \mathrm{HCl}$ for sample solutions prepared in water and ethanol, and for $0.3 \%(\mathrm{~m} / \mathrm{v}) \mathrm{K}_{3} \mathrm{Fe}(\mathrm{CN})_{6}$ solution. The concentration of $\mathrm{K}_{3} \mathrm{Fe}(\mathrm{CN})_{6}$ required to convert $\mathrm{Pb}(\mathrm{II})$ to $\mathrm{Pb}(\mathrm{IV})$ was optimized by increasing the concentration from 1 to $10 \%(\mathrm{~m} / \mathrm{v})$ in $0.03 \% \mathrm{HCl}$ solution. Sodium borohyride concentration was adopted as $0.2 \%(\mathrm{~m} / \mathrm{v})$ from a previous work [12].

The temperature of the atomization cell affects the complete atomization of $\mathrm{Pb}$ from plumbane, which is controlled by the acetylene/air composition of the flame [5]. To optimize the atomization temperature, the flow rate of acetylene was varied between 2.0 and $3.5 \mathrm{~L} \mathrm{~min}^{-1}$ by maintaining the air-flow at $8 \mathrm{~L} \mathrm{~min}^{-1}$; the peak height absorbance of $\mathrm{Pb}$ from atomization of $\mathrm{PbH}_{4}$ was monitored for maximum sensitivity. Then, the flow rate of air was investigated in range of 8-12 $\mathrm{L} \mathrm{min}^{-1}$ at the optimum acetylene flow rate. This optimization was also carried out with sample solutions prepared in ethanol.

\subsection{Interferences}

Ethanol, potassium tartrate, dextrose or sugar and tartaric acid are the major components of alcoholic beverages (e.g., wine and rum). The performance of the procedure due to the interferences caused by these species was investigated for each individual component separately. Individual components were deemed not to cause interference if the absorbance was within $\pm 5 \%$ of that from $\mathrm{Pb}$ in aqueous solution. The tolerance limits to the interferents, expressed as the maximum concentration with no significant deleterious effect, were also determined.

\subsection{Method validation}

The accuracy of the method was validated by the analysis of wine and rum samples spiked with $\mathrm{Pb}$. To do this, $1.5 \mathrm{~mL}$ of Californian wine and $1 \mathrm{~mL}$ of Italian wine were first acidified with $40 \mu \mathrm{L}$ of concentrated $\mathrm{HCl}$. The Californian wine samples were spiked with either 20,40 or $60 \mu \mathrm{L}$ of $1 \mu \mathrm{g} \mathrm{mL}^{-1} \mathrm{~Pb}$ solution, while those of Italian wine were spiked with either $10,20,30$ or $40 \mu \mathrm{L}$ of $1 \mu \mathrm{g} \mathrm{mL}^{-1}$ $\mathrm{Pb}$ solution. The solutions were diluted to $10 \mathrm{~mL}$ with water yielding $\mathrm{Pb}$ spikes either 2.0, 4.0, and $6.0 \mu \mathrm{g} \mathrm{L}^{-1}$ for the Californian wine, and $1.0,2.0,3.0$ or $4.0 \mu \mathrm{g} \mathrm{L}^{-1}$ for the Italian wine. In the case of rum, $10 \mathrm{~mL}$ of rum sample was first acidified with $30 \mu \mathrm{L}$ of concentrated $\mathrm{HCl}$ and then spiked with either 10, 20, 40 and $60 \mu \mathrm{L}$ of $1 \mu \mathrm{g} \mathrm{mL}^{-1}$ $\mathrm{Pb}$ solution that introduced either $1.0,2.0,4.0$ or $6.0 \mu \mathrm{g} \mathrm{L}^{-1} \mathrm{~Pb}$ to the rum sample. After these simple pre-treatments, samples were analyzed for $\mathrm{Pb}$ by the hydride generation AAS. Calibration was made by external standards ranging from 0.0 to $8.0 \mu \mathrm{g} \mathrm{L}^{-1} \mathrm{~Pb}$ prepared in $0.30 \%(\mathrm{v} / \mathrm{v}) \mathrm{HCl}$.

The results of the hydride generation method were also verified by the analysis of the samples using the reference method by ICPMS [30]. The reference method was based on the dilution of the wine and rum solutions at one-to-two ratio (1:2) with deionized water. Calibration standards were prepared in water and ethanol. Ethanol content was about 5-6\% (v/v) for matrix matching of the alcohol content of the 1:2 diluted wine samples. For the rum, the content of alcohol was about $20 \%(\mathrm{v} / \mathrm{v})$.

\section{Results and discussion}

\subsection{Effects of argon flow rate, mixing coil, reaction coil and sample volume}

The effect of argon stripping gas flow rate on the peak height absorbance was evaluated by varying from 10 to $100 \mathrm{~mL} \mathrm{~min}^{-1}$. Maximum absorbance was obtained between 20 and $25 \mathrm{~mL} \mathrm{~min}^{-1}$. The flow rate was maintained at $22 \mathrm{~mL} \mathrm{~min}^{-1}$ throughout the study. While the low absorbance at lower argon flow rates was thought to occur due to the decomposition of relatively unstable $\mathrm{PbH}_{4}$ before reaching the atomizer, that at higher flow rates was most likely due to the deposition of the salts on the inner surface of quartz tube. Above $60 \mathrm{~mL} \mathrm{~min}^{-1}$, there was a substantial bubble formation in the gas-liquid separator that resulted in the transfer of the liquid droplets to the atomizer tube.

The optimum length of the mixing coil was chosen as $60 \mathrm{~cm}$ to ensure complete mixing and in turn oxidation of $\mathrm{Pb}$ (II) to $\mathrm{Pb}(\mathrm{IV})$ by $\mathrm{K}_{3} \mathrm{Fe}(\mathrm{CN})_{6}$ solution. However, it should be noted that the peak height absorbances obtained with $25-70 \mathrm{~cm}$ long mixing coils were virtually the same. Conversely, the length of the reaction coil on the chemfold had no significant effect over the range $(15-30 \mathrm{~cm})$ investigated, indicating that all $\mathrm{Pb}$ (IV) was fully converted to $\mathrm{PbH}_{4}$. 
Table 1

The effect of the flow rates of carrier and $3 \%(\mathrm{~m} / \mathrm{v}) \mathrm{K}_{3} \mathrm{Fe}(\mathrm{CN})_{6}$ solutions on the absorbance of $\mathrm{Pb}\left(\mathrm{Pb}: 4 \mu \mathrm{g} \mathrm{L}^{-1}\right.$, flow rate of $\mathrm{NaBH}_{4}: 5.4 \mathrm{~mL} \mathrm{~min}^{-1}$ )

\begin{tabular}{lccc}
\hline Step & \multicolumn{2}{l}{ Flow rate $\left(\mathrm{mL} \mathrm{min}^{-1}\right)$} & Relative absorbance \\
\cline { 2 - 3 } & Carrier & $\mathrm{K}_{3} \mathrm{Fe}(\mathrm{CN})_{6}$ & \\
\hline 1 & 4.2 & 4.2 & 0.50 \\
2 & 5.0 & 5.0 & 0.65 \\
3 & 5.0 & 11.4 & 0.91 \\
4 & 11.4 & 11.4 & 1.00 \\
5 & 11.4 & 12.6 & 0.94 \\
\hline
\end{tabular}

A $20 \mathrm{~cm}$ long PTFE tubing $(0.8 \mathrm{~mm}$ i.d.) was used as reaction coil thereafter. Similarly, no significant variations were observed in the peak height absorbance when the volume of sample (e.g., volume of sample loop) increased from 100 to $200 \mu \mathrm{L}$. Absorbance peaks broadened above $200 \mu \mathrm{L}$ and double peaks were observed with further increases in the sample volume. To avoid these problems, the volume of the sample loop was adjusted to $170 \mu \mathrm{L}$. Flow rates of the solutions were optimized using the volume of the sample loop.

\subsection{Effect of carrier, oxidant and reductant flow rates}

The dilution/dispersion of the sample within the reagent and carrier streams reduces the analytical signal (e.g., absorbance) in a flow injection system. In hydride generation, the dilution within the gas-liquid separator also adds to the reduction in the sensitivity. The flow rates of the solutions are therefore as critical as that of argon stripping gas to transport $\mathrm{PbH}_{4}$ to the gas-liquid separator with minimum dilution/dispersion following the reactions with $\mathrm{K}_{3} \mathrm{Fe}(\mathrm{CN})_{6}$ and $\mathrm{NaBH}_{4}$. The results summarizing the effects of the flow rates of the solutions on the peak height absorbance are given in Table 1. The absorbance of $\mathrm{Pb}$ increased with increasing flow rates of both carrier stream and the $\mathrm{K}_{3} \mathrm{Fe}(\mathrm{CN})_{6}$ solution. Comparison of the absorbances obtained in Steps 1,2 and 4, which all had the same degree of dilution $(1: 1)$ suggests that there was a substantial dispersion of the sample at lower flow rates. The flow rate of $\mathrm{K}_{3} \mathrm{Fe}(\mathrm{CN})_{6}$ solution had the highest influence on the signal as it could clearly be seen from the comparison of the absorbances obtained in Steps 2 and 3. Despite a dilution greater than two-fold, the absorbance at Step 3 was higher by about 30\% than that at Step 2. Comparison of the absorbances at Steps 3 and 4 also supports this finding; absorbance at Step 3 was lower by only 10\% than that at Step 4. Another implication of the latter is that increasing or decreasing the flow rate of the carrier was not very influential on the absorbance signal provided that flow rate of $\mathrm{K}_{3} \mathrm{Fe}(\mathrm{CN})_{6}$ solution was at the optimum value. As for the concentration of $\mathrm{K}_{3} \mathrm{Fe}(\mathrm{CN})_{6}$, the optimum value was around $3 \%(\mathrm{~m} / \mathrm{v})$ that afforded a complete oxidation of $\mathrm{Pb}(\mathrm{II})$ to $\mathrm{Pb}(\mathrm{IV})$. Unlike $\mathrm{K}_{3} \mathrm{Fe}(\mathrm{CN})_{6}$, the flow rate of the sodium borohydride $\left(\mathrm{NaBH}_{4}\right)$ solution did not provide any significant improvement in the absorbance when it was varied between 4.2 and $11.4 \mathrm{~mL} \mathrm{~min}^{-1}$. Similarly, its concentration was sufficient at $0.2 \%(\mathrm{~m} / \mathrm{v})$; maximum concentration examined was $2.0 \%(\mathrm{~m} / \mathrm{v})$. The flow rate of $\mathrm{NaBH}_{4}$ was set to $5.4 \mathrm{~mL} \mathrm{~min}^{-1}$ and the concentration was kept at $0.2 \%(\mathrm{~m} / \mathrm{v})$ to minimize contamination from $\mathrm{NaBH}_{4}$.

\subsection{Effects of sample acidity and atomization temperature}

The efficiency of generation of $\mathrm{PbH}_{4}$ is highly dependent of the acidity of the sample and oxidant solutions $\left(\mathrm{K}_{3} \mathrm{Fe}(\mathrm{CN})_{6}\right)$, which in turn determines the acidity of the reaction medium. The results for the effect of the initial acidity $(\mathrm{HCl} \%)$ of the sample and potassium ferricyanide are illustrated in Fig. 2. The optimum concentration of $\mathrm{HCl}$ was about $0.30 \%(\mathrm{v} / \mathrm{v})$ for samples prepared in water and ethanol, while that for $\mathrm{K}_{3} \mathrm{Fe}(\mathrm{CN})_{6}$ was $0.03 \%(\mathrm{v} / \mathrm{v}) \mathrm{HCl}$. Double peaks

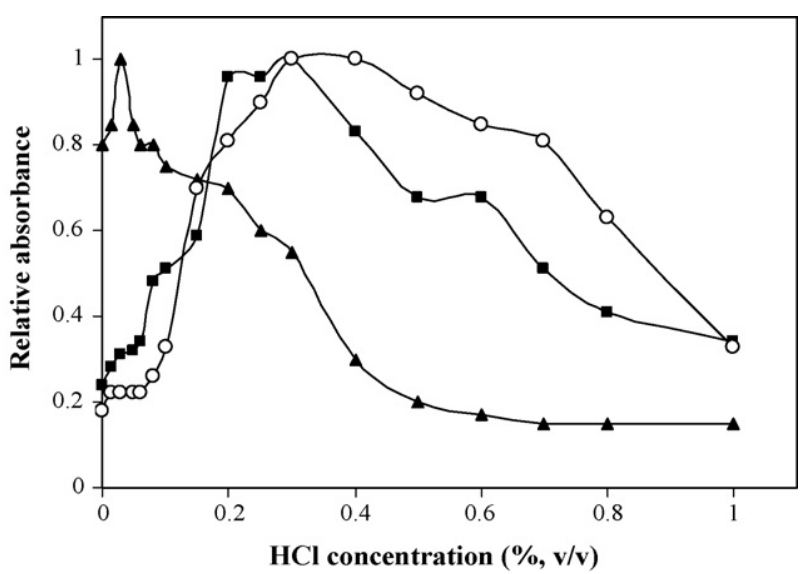

Fig. 2. Variation of $\mathrm{Pb}$ absorbance with the concentration of $\mathrm{HCl}(\boldsymbol{\square})$ in water, $(\bigcirc)$ in ethanol, $(\boldsymbol{\Delta})$ in $3 \%(\mathrm{~m} / \mathrm{v}) \mathrm{K}_{3} \mathrm{Fe}(\mathrm{CN})_{6}$.

formed for sample solutions when the acidity of $\mathrm{K}_{3} \mathrm{Fe}(\mathrm{CN})_{6}$ solution increased to $0.30 \%(\mathrm{v} / \mathrm{v}) \mathrm{HCl}$ (same acidity with sample solution). As the concentration of $\mathrm{HCl}$ in the sample solution increased to $0.40 \%$ $(\mathrm{v} / \mathrm{v}) \mathrm{HCl}$, the absorbance peaks first became flat-top and broadened that consequently resulted in the loss of peak height sensitivity. Further increase in $\mathrm{HCl}$ concentration to $0.50 \%(\mathrm{v} / \mathrm{v})$ had the same effect as that observed with $\mathrm{K}_{3} \mathrm{Fe}(\mathrm{CN})_{6}$ in $0.30 \%(\mathrm{v} / \mathrm{v} \mathrm{HCl})$; double peaks formed. The peaks separated from each other as the acid concentration increased, which was not investigated in our study. There was not any significant difference in the peak height absorbance whether the carrier stream was deionized water or $0.30 \%(\mathrm{v} / \mathrm{v}) \mathrm{HCl}$. The same behavior was observed for solutions prepared in ethanol, thus, water was used throughout as the carrier.

The peak height absorbance of $\mathrm{Pb}$ from aqueous solutions was not affected from the variations in acetylene flow rate between 2 and $3.5 \mathrm{~L} \mathrm{~min}^{-1}$ when air-flow rate was $8 \mathrm{~L} \mathrm{~min}^{-1}$. However, carbon deposition on the inner surface of the quartz tube was observed when acetylene flow rate was greater than $2.5 \mathrm{~L} \mathrm{~min}^{-1}$. Changing the air-flow rate from 8 to $12 \mathrm{~L} \mathrm{~min}^{-1}$ did not affect the absorbance at all. The optimum flow rates of the flame gases were adjusted to 2.5 and $10 \mathrm{~L} \mathrm{~min}^{-1}$ for acetylene and air, respectively. For solutions prepared in ethanol, the composition of acetylene-air was reoptimized as $1.5-10 \mathrm{~L} \mathrm{~min}^{-1}$ (highly oxidizing) to avoid the high background originated from the organics components of the samples.

\subsection{Effects of major components in wine}

The major components of wine and rum are ethanol, potassium tartrate, dextrose or sugar, and tartaric acid. No significant effects were observed from ethanol (up to almost 100\%), potassium tartrate (up to $1 \%, \mathrm{~m} / \mathrm{v}$ ) and dextrose (up to $5 \%, \mathrm{~m} / \mathrm{v}$ ) on the generation of lead hydride and consequently the absorbance. The results for ethanol were different from that reported by Cacho et al. [25], who observed interference from ethanol using $\mathrm{H}_{2} \mathrm{O}_{2}$ as oxidizing agent in analysis of wine samples for lead. This was probably due to the differences in the performance of the oxidizing agents, $\mathrm{K}_{3} \mathrm{Fe}(\mathrm{CN})_{6}$ and $\mathrm{H}_{2} \mathrm{O}_{2}$, used to convert $\mathrm{P}(\mathrm{II})$ to $\mathrm{Pb}(\mathrm{IV})$. Flame fuel/air ratio may have also contributed to the interference from ethanol reported by Cacho et al. [25], as it necessitates a highly oxidizing flame to overcome the high background. In the presence of tartaric acid, the peak height absorbance of $\mathrm{Pb}$ reduced due to the tartaric acid concentration exceeded $0.4 \%(\mathrm{~m} / \mathrm{v})$ in the sample solution. The reduction in the signal profile was similar to that observed with $\mathrm{HCl}$ concentration greater than $0.4 \%(v / v)$. When compared with potassium tartrate, the suppression or decrease in hydride generation 
Table 2

The results for tests of addition/recovery for lead spiked into rum and diluted wine samples $(n=3)$

\begin{tabular}{lllr}
\hline Sample & \multicolumn{2}{l}{ Pb Concentration $\left(\mu \mathrm{g} \mathrm{L}^{-1}\right)$} & Recovery (\%) \\
\cline { 2 - 3 } & Added & Found & \\
\hline Californian red wine (1.5:10 diluted) & 0.0 & 0.69 & - \\
& 2.0 & 2.65 & 98 \\
& 4.0 & 4.85 & 104 \\
& 6.0 & 7.11 & 107 \\
Italian red wine (1:10 diluted) & 0.0 & 2.47 & - \\
& 1.0 & 3.47 & 100 \\
& 2.0 & 4.67 & 110 \\
& 3.0 & 5.59 & 104 \\
Rum (no dilution) & 4.0 & 6.51 & 101 \\
& 0.0 & 1.22 & - \\
& 1.0 & 2.26 & 104 \\
& 2.0 & 3.18 & 98 \\
& 4.0 & 5.03 & 95 \\
\hline
\end{tabular}

efficiency with tartaric acid was attributed to the increased acidity of the sample solution as also reported in a previous work [25].

\subsection{Analytical figures of merits}

In the presence of the matrices, the recoveries of $\mathrm{Pb}$ from wine and rum samples spiked with $\mathrm{Pb}$ were found to test of accuracy of the proposed method. Recoveries obtained by external calibration from the spiked wine samples varied between 98 and 110\%, and that for the rum were between 95 and 104\% (Table 2).

The peak height absorbance signal was linear up to $8.0 \mu \mathrm{g} \mathrm{L}^{-1}$ $\mathrm{Pb}$ with a regression coefficient of 0.998 . The characteristic concentration ( 0.0044 absorbance) was $0.56 \mu \mathrm{g} \mathrm{L}^{-1} \mathrm{~Pb}$. The detection limit was $0.16 \mu \mathrm{g} \mathrm{L}^{-1} \mathrm{~Pb}$, which was calculated as three times the standard deviation of the absorbance of blank solutions $(n=10)$.

\subsection{Determination of $\mathrm{Pb}$ in red wine and rum}

Red wine has a complex matrix because of the presence of the organic components whose effects were discussed above. Another major hurdle in the analysis of red wine by hydride generation was the foaming within the gas-liquid separator. When the red wine was diluted with water at least 1:7 ratio, the bubbling/foaming was eliminated. Because the sample acidity was very critical for efficient generation of $\mathrm{PbH}_{4}$, the effect of acidity for the diluted samples was reexamined between 0.20 and $0.50 \%(\mathrm{v} / \mathrm{v}) \mathrm{HCl}$. The best peak height absorbance was achieved at $0.40 \%(\mathrm{v} / \mathrm{v}) \mathrm{HCl}$. The absorbance was lower at lower acidity, and peak broadening and splitting occurred above $0.40 \%(\mathrm{v} / \mathrm{v}) \mathrm{HCl}$. For rum, no dilution was made and $10 \mathrm{~mL}$ of bottled rum was acidified to $0.30 \%(\mathrm{v} / \mathrm{v}$ ) $\mathrm{HCl}$ by adding $30 \mu \mathrm{L}$ of concentrated $\mathrm{HCl}$

The results from the analysis of diluted red wine samples acidified to $0.40 \%(\mathrm{v} / \mathrm{v}) \mathrm{HCl}$ and rum sample in $0.30 \%(\mathrm{v} / \mathrm{v}) \mathrm{HCl}$ are given in Table 3. The content of lead obtained by FI-HG-AAS was verified by analyzing the diluted wine and rum samples by ICP-MS using the reference method [30]. There was no significant difference between

Table 3

Determination of $\mathrm{Pb}$ in wine and rum samples by FI-HG-AAS and ICP-MS $(P=0.95)$

\begin{tabular}{llll}
\hline Sample & \multicolumn{2}{l}{ Pb concentration $\left(\mu \mathrm{g} \mathrm{L}^{-1}\right)$} & \multirow{2}{*}{ Error (\%) } \\
\cline { 2 - 3 } & $\operatorname{HG}-\mathrm{AAS}(n=7)$ & ICP-MS $(n=4)$ & \\
\hline Californian red wine & $4.79 \pm 0.43$ & $4.99 \pm 0.10$ & -4.01 \\
Italian red wine & $25.8 \pm 1.5$ & $25.2 \pm 2.8$ & +2.38 \\
Rum & $1.25 \pm 0.14$ & $1.31 \pm 0.20$ & -4.58 \\
\hline
\end{tabular}

the $\mathrm{Pb}$ concentrations of the wine and rum samples, determined by FI-HG-AAS and ICP-MS at 95\% confidence level. The relative errors were in range of $-4.58 \%$ and $+2.38 \%$. The relative standard deviations were $6.1 \%$ for Italian wine $(n=7), 9.6 \%$ for Californian wine $(n=7)$ and $12.0 \%$ for the rum $(n=3)$.

\section{Conclusion}

A flow injection hydride method is described for determination of $\mathrm{Pb}$ in wine and rum samples by FAAS. The method is simple, fast and provides accurate results. Sample pretreatment, except dilution, is not necessary. Possible background interferences from the organics and ethanol can easily be eliminated by adjusting acetylene/air flow rates in the flame heated the quartz tube.

The method described was used to determine lead in a limited number of alcoholic beverages. Therefore, the application of the method in analysis of other alcoholic beverages requires special consideration because of different complex matrices, changed from sample to sample. It is concluded that the method can be used for routine analysis of high alcohol (e.g., ethanol) content beverages for $\mathrm{Pb}$.

\section{Acknowledgement}

L. Elçi is grateful to The Scientific and Technological Research Council of Turkey (TUBITAK) for financial support during the course of the study.

\section{References}

[1] T. Nielsen, K.A. Jensen, P. Grandjean, Organic lead in normal human brains, Nature 274 (1978) 602-603.

[2] C.S. Ough, Lead in wines-a review of recent reports, Am. J. Enol. Vitic. 44 (1993) 464-467.

[3] P.A. Brereton, P. Robb, C.M. Sargent, H.M. Crews, R. Wood, Determination of lead in wine by graphite furnace atomic absorption spectrometry: interlaboratory study, J. AOAC Int. 80 (1997) 1287-1297.

[4] J. Dedina, D.L. Tsalev, Hyride Generation Atomic Absorption Spectrometry., John Wiley \& Sons, Chichester, 1995

[5] Y. Madrid, C. Camara, Lead hydride generation atomic absorption spectrometry: an alternative to electrothermal atomic absorption spectrometry, a review, Analyst 119 (1994) 1647-1658.

[6] J.R. Castillo, J.M. Mir, C. Martinez, J. Vol, P. Colon, Influence of oxidising agents in lead determination by hydride generation direct flame atomic absorption spectroscopy, Mikrochim. Acta 85 (1985) 253-263.

[7] P.K. Hon, O.W. Lau, W.C. Cheung, M.C. Wong, The atomic absorption spectrometric determination of arsenic, bismuth, lead, antimony, selenium and tin with a flame- heated silica t-tube after hydride generation, Anal. Chim. Acta 115 (1980) 355-359.

[8] K. Jin, M. Taga, Determination of lead by continuous-flow hydride generation and atomic absorption spectrometry: comparison of malic acid-dichromate, nitric acid-hydrogen peroxide and nitric acid-peroxodisulfate reaction matrices in combination with sodium tetrahydroborate, Anal. Chim. Acta 143 (1982) 229-236.

[9] C.M. Mena, C.M. Cabrera, L. Lorenzo, M.C. Lopez, Determination of lead contamination in Spanish wines and other alcoholic beverages by flow injection atomic absorption spectrometry, J. Agric. Food Chem. 45 (1997) 1812-1815.

[10] N. Maleki, A. Safavi, Z. Ramezani, Determination of lead by hydride generation atomic absorption spectrometry (HGAAS) using a solid medium for generating hydride, J. Anal. At. Spectrom. 14 (1999) 1227-1230.

[11] R. Thao, H. Zhou, Determination of Pb in foods by HGAAS, Fenxi Huaxue 13 (1985) 283-285

[12] E. Nusret, Z. Arslan, J.F. Tyson, Determination of lead using flow injection hydride generation atom trapping flame atomic absorption spectrometry. Colloquium Spectroscopium Internationale XXXI, Book of Abstracts, Ankara, Turkey (1999) 80.

[13] Y. Madrid, J. Meseguer, M. Bonilla, C. Camara, Lead hydride generation in a lactic acid-potassium dichromate medium and its application to the determination of lead in fish, vegetable and drink samples, Anal. Chim. Acta 237 (1990) 181-187.

[14] Y. Madrid, D. Chakraborti, C. Camara, Evalution of flow-injection in lead hyride generation-atomic absorption spectrometry, Microchim. Acta 120 (1995) 63-72.

[15] A. Berkkan, N. Ertaş, Determination of lead in dialysis concentrates using flow injection hydride generation atomic absorption spectrometry, Talanta 64 (2004) 423-427. 
[16] O. Cankur, D. Korkmaz, O.Y. Ataman, Flow injection-hydride generationinfrared spectrophotometric determination of Pb, Talanta 66 (2005) 789-793.

[17] W. Chuachuad, J.F. Tyson, Determination of lead by flow injection hydride generation atomic absorption spectrometry with tetrahydroborate immobilized on an anion-exchange resin, J. Anal. At. Spectrom. 20 (2005) 282-288.

[18] H.O. Haug, Study on stable coatings for determination of lead by flow-injection hydride generation and in situ concentration in graphite furnace atomic absorption spectrometry, Spectrochim. Acta 51 B (1996) 1425-1433.

[19] Z. Shu-Zhen, H. Heng-Bin, N. Zhe-Ming, Determination of lead by hydride generation atomic absorption spectrometry in the presence of nitroso-R salt, Anal. Chim. Acta 221 (1989) 85-90.

[20] J.F. Tyson, R.I. Ellis, G. Carnrick, F. Fernandez, Flow injection hydride generation electrothermal atomic absorption spectrometry with in-atomizer trapping for the determination of lead in calcium supplements, Talanta 52 (2000) 403-410.

[21] I.D. Brindle, R. Mc Laughlin, N. Tangtreamjitmun, Determination of lead in calcium carbonate by flow-injection hydride generation with dc plasma atomic emission detection, Spectrochim. Acta 53B (1998) 1121-1129.

[22] T. Qing, W. Peng, W. Li, H. Xiandeng, Sensitive determination of lead by flame atomic absorption spectrometry improved with branched capillary as hydride generator and without phase separation, Microchim. Acta 155 (2006) 441 445.
[23] C. Nerin, S. Olavide, J. Cacho, Behavior of several lead compounds in organic medium with a hydride generator: direct determination of lead in gasoline, Anal. Chem. 59 (1987) 1918-1921.

[24] J.J. Aznárez, F. Palacios, J.C. Vidal, J. Galbán, Extraction-atomic absorption spectrophotometric determination of lead by hydride generation in non-aqueous media, Analyst 109 (1984) 713-715

[25] J. Cacho, V. Ferreira, C. Nerín, Determination of lead in wines by hydride generation atomic absorption spectrometry, Analyst 117 (1992) 31-33.

[26] J. Sanz, P. Basterra, J. Galban, J.R. Castillo, Direct lead determination in wine by hydride generation-atomic absorption spectrometry, Microchim. Acta 97 (1989) 271-279.

[27] J. Sanz, P. Basterra, J. Galban, J.R. Castillo, Some observations on the use of a hydride generation flame-heated silica tube atomic absorption spectrometric system for the determination of lead in wine, Microchem. J. 40 (1989) 115-124.

[28] C.B. Santos, A.G. Portal, Application of hydride generation to atomic-absorption spectrometric analysis of wines and beverages: a review, Talanta 39 (1992) 329-339.

[29] K. Pyrzyǐnska, Analytical methods for the determination of trace metals in wine, Crit. Rev. Anal. Chem. 34 (2004) 69-83.

[30] A. Stroh, P. Brückner, U. Völlkopf, Multielement analysis of wine samples using ICP-MS, At. Spectrosc. 15 (1994) 100-106. 